\title{
AMSSM position statement update: blood-borne pathogens in the context of sports participation
}

\author{
Christopher McGrew (D) ,,2 Daisy-Scarlett MacCallum, ${ }^{3}$ Dustymarie Narducci, ${ }^{4}$ \\ Rathna Nuti (D , ${ }^{5}$ Leonard Calabrese, ${ }^{6}$ Robert J Dimeff, ${ }^{7}$ Stephen Paul, ${ }^{8}$ \\ Sourav Poddar, ${ }^{9}$ Ashwin Rao, ${ }^{10}$ Douglas McKeag ${ }^{11}$
}

For numbered affiliations see end of article.

\section{Correspondence to} Dr Christopher McGrew, Family and Community Medicine Unversity of New Mexico Health Sciences Center, Abuquerque New Mexico 87114, USAOrthopedics and Rehabilitation, Sports Medicine Division, University of New Mexico Health Sciences Center, Albuquerque New Mexico 87114, USA;

chrismcgrew1958@gmail.com

This article has been copublished in the British Journal of Sports Medicine and Clinical Journal of Sport Medicine.

Received 29 January 2019 Accepted 30 January 2019 Published Online First 19 March 2019

\section{ABSTRACT}

This American Medical Society for Sports Medicine position statement update is directed towards healthcare providers of patients involved in sport and exercise. There have been significant advances in clinical and scientific research in the understanding of bloodborne pathogens (BBPs), and this update incorporates these advancements. This document is intended as a general guide to clinical practice based on the current state of the evidence, while acknowledging the need for modification as new knowledge becomes available. Confirmed transmission of BBPs during sport is exceedingly rare. There are no well-documented reports of HIV, HCV or HDV transmission during sport. There is also no evidence for universal testing for BBPs as a specific requirement for participation in sports. Competitive athletes and non-athletes should follow appropriate general public health agency recommendations for screening for BBPs, considering their individual risk factors and exposures. Standard (universal) precautions must be followed by those providing care to athletes. Exercise and athletic participation can help promote a healthy lifestyle for persons living with BBPs. Those with acute symptomatic BBP infection should limit exercise intensity based on their current health status. Education is the key tool for preventing BBP transmission. Research gaps include evaluation of the prevalence of BBP infections in competitive athletes, the effects of long-term, intense training on infected athletes and the effects of BBP treatment therapies on performance.

\section{INTRODUCTION}

The past 20 years have witnessed significant advances in clinical and scientific research in the understanding of blood-borne pathogens (BBPs). Prior to 1995 , there was limited scientific information concerning BBP including HIV, hepatitis B virus (HBV), hepatitis $\mathrm{C}$ virus (HCV) and hepatitis $\mathrm{D}$ virus (HDV) as they are related to sports and athletic participation. This substantial knowledge deficit led to misunderstanding and misinformation about sports-related transmission risks and whether exercise participation for those harbouring these conditions should be permitted. In recognition of growing concerns by sports physicians and other healthcare providers, both the American Medical Society for Sports Medicine (AMSSM) and American Orthopaedic Society for Sports Medicine (AOSSM) responded by examining then-known medical science of BBPs as related to sports participation. ${ }^{1}$ Other groups followed with their own sports-related HIV/AIDs/BBP statements. ${ }^{2-9}$ Subsequent scientific and clinical research has led to significant advances in our understanding of BBPs.

This AMSSM position statement update, directed towards all healthcare providers who care of patients involved in sport and exercise, incorporates these advancements. This document is intended to act as a general guide to clinical practice based on the current state of the evidence, while acknowledging the need for modification as new knowledge becomes available.

\section{Epidemiology and transmission-general considerations: HIV, HBV, HCV and HDV}

The prevalence of BBPs among athletes has not been studied extensively. A 1995 study evaluated the prevalence of HBV infection in South Australian soccer players and found no difference compared with a group of blood donors of the same age. ${ }^{10} \mathrm{~A}$ 2008 study examined the prevalence of HCV in 208 former professional and amateur Brazilian soccer and basketball players. It reported a prevalence of $7.2 \%$, with values of $11 \%$ among professionals and $5.5 \%$ among amateurs. ${ }^{11}$ The study found a close correlation between the use of injectable stimulants and HCV infection rates. In comparison, the prevalence of BBPs in athletes who did not inject such drugs was $0.6 \%$, suggesting that sports participation itself had little to do with the relatively high overall prevalence rates. A 2011 study involving 420 male wrestlers (high-contact sport) and 205 volleyball and soccer players (low to moderate contact sports) found no evidence that participation in wrestling led to higher rates of HBV or HCV transmission compared with low-contact to moderate-contact sports. ${ }^{12}$

In athletic practices and competition, the potential route of transmission for BBPs occurs via blood from direct contact between an infected athlete with disrupted skin and/or mucous membranes of an uninfected athlete. Analysis of PCR for HIV RNA and pro-viral DNA present in eccrine sweat has verified that HIV is not transmitted through sweat or saliva. ${ }^{13-15}$ Key biological characteristics of BBPs relevant to the potential for transmission in athletic settings include: (1) HIV has the lowest stability/ infectivity and hepatitis B has the highest stability/ infectivity, (2) the molecular structure of the HBV allows the virus to withstand environmental surfaces for $\geq 1$ weeks and (3) HBV is highly concentrated in infected individuals making the speculative transmission risk higher when compared with HIV and HCV. ${ }^{13} 1516$ Transmission of HCV and HIV in the 
healthcare setting remains a serious concern. Although rare, it is recommended that dental treatment should be included among the risk factors of HBV and HCV infection. Multiple case reports describe possible HCV transmission via blood splash into the conjunctiva, although the viral load of the splash donors has not been reported in these cases, therefore, no infection risk has been estimated. Among the reported cases, no phylogenetic analysis has been reported between donor and recipient HCV. Risk of transmission via these methods can easily be eliminated using standard precautionary measures. ${ }^{15-18}$

Similar to the non-athletic population, high-risk behaviours outside of competition and practice, such as unprotected sex and the sharing of injection-related equipment, present the most likely route of transmission. HIV is not transmissible through casual contact, swimming pools, mosquitoes, saliva, sweat, tears, urine, faeces and inanimate objects (ie, wrestling mats, toilet seats and sinks). Sharing of objects such as razors and toothbrushes carries at least a theoretical risk of infection and should be avoided. ${ }^{19-24}$

\section{Human immunodeficiency virus}

Approximately 37 million people worldwide are currently infected with HIV, with an estimated 2.45 million new diagnoses annually. ${ }^{25}$ Sub-Saharan Africa has the highest prevalence of HIV. New infections worldwide show declining trends. ${ }^{25}$ In the USA, approximately 1.2 million individuals are living with HIV (compared with 1 million in 1995) with approximately 40000 new infections diagnosed every year. New infections in the USA are declining, consistent with global trends, though prevalence increases the success of highly active antiretroviral therapy (HAART) and other life-extending treatments. ${ }^{26}$

HIV is transmitted through sexual contact, parenteral exposure to blood and blood components, contamination of infected blood into open wounds or mucous membranes and perinatally from an infected mother to fetus or infant. There is no evidence of transmission via other routes, such as contact in a household or athletic venue or by viral particles in droplets suspended in the air. Transmission of HIV by sexual contact is reduced to an extremely low rate for infected patients managed with suppressive HIV treatment. ${ }^{27}$

There are no well-documented, confirmed reports of HIV transmission during sport. Only one instance of HIV infection thought to be possibly related to sports was reported in a 'letter to the editor' in the medical literature. In this report, the infection was diagnosed in a recreational soccer player in Italy following head-to-head contact with another player who was infected with $\mathrm{HIV}^{28}$ Public health officials in Italy, who reviewed the available data from this case, found that testing was not done on either athlete at the time of the incident, and thus, non-athletic risk factors could not be reasonably excluded. ${ }^{29}$ In the over 27 years since this report was published, there have been no additional reported cases of HIV transmission during sport.

The theoretical risk for transmission of HIV has been estimated in the National Football League (NFL) to be $<1$ per 85 million game contacts or $<1$ transmission in 58.6 seasons. ${ }^{30}$ This lowrisk assessment is likely overinflated, as it was determined using the number of observed bleeding injuries during one season and then correlating to the risk of percutaneous HIV transmission involving hollow bore needles in the healthcare setting. This would not be directly applicable to athletic scenarios.

Although not the equivalent of sanctioned combative sports such as boxing and mixed martial arts, transmission of HIV in street fighting has been documented in case reports. ${ }^{31}$ Increased risk for transmission was associated with high-risk behaviours (unprotected sex and needle sharing) and was tremendously reduced in any population if the infected individual was being treated with antiretroviral therapy (ART). ${ }^{2732}$

\section{Hepatitis B virus/Hepatitis D virus}

Approximately two billion people worldwide have evidence of past or present infection with HBV, and 248 million individuals are chronic carriers (ie, positive for HBV surface antigen). ${ }^{33}$ Acute hepatitis B has been declining in incidence since 1990 mainly due to effective preventive strategies such as vaccination. The Centres for Disease Control (CDC) estimates a US prevalence of approximately $2 \%$ with a reported 2953 acute HBV cases in 2014. ${ }^{34}$ The number of Americans who are living with chronic HBV infection is growing due to the increasing prevalence of chronic carriers, despite a gradual decline in new cases. Recent CDC investigations report approximately 2.2 million chronic carriers in the USA. ${ }^{34}$

HBV is spread by percutaneous and mucous membrane exposures to infectious body fluids (ie, serum, semen and saliva). The risk of transmission of HBV is $50-100$ times higher than that of transmission of HIV. ${ }^{35}$ Explanations for this difference may include the fact that HBV is far more concentrated in blood, more stable in the environment and can survive ex vivo for up to 7 days with the capability of causing infection during this period.

The body of evidence for transmission of HBV in sports activity is limited to three case series dated before the year 2000 . There are no recent reports to delineate the current risk. HBV transmission was documented in Japan in 5 members of a high school sumo-wrestling club ${ }^{36}$ and 11 members of a Japanese University American Football Team. ${ }^{37}$ In both studies, the horizontal transmission came from an index case through compromised skin contamination to a presumed contact. In addition, over a 6-year period, a cluster of 568 cases of HBV infection was reported in Swedish cross-country track finders (orienteering). ${ }^{38}$ Inoculation with $\mathrm{HBV}$ during competition during the first outbreak was thought to have occurred from blood transmission from shrubs on which infected athletes had scraped themselves and from the sharing of bathtubs post-race. The authors contend that although more than one mode of transmission contributed to the spread of the disease, the likely infectious mode of transmission occurred through postcompetition common bathing. Of note, the epidemic was controlled when regulations introducing adequate protective clothing for competitors were enforced. In the nearly two decades since the last of these isolated and remote case series occurred, there have been no new published reports.

There are no published estimates of the risk of HBV transmission during sport, but extrapolation from NFL-based reports for HIV gives an estimate of one transmission in every 850000 to 4.25 million game contacts for $\mathrm{HBV}^{39}$ an extrapolation based off of the significantly flawed approach of the original NFL calculation for potential HIV transmission. ${ }^{30}$

$\mathrm{HDV}$ is a defective RNA virus that requires HBV for assembly, replication and transmission and thus can only infect those who concurrently have $\mathrm{HBV}^{4041}$ An estimated 10-20 million individuals are co-infected with HDV worldwide with a greater relative prevalence in the USA, Australia and Europe. ${ }^{41-43}$ The modes of transmission of HDV are the same as for HBV, via blood products and body fluids. ${ }^{40} 4143$

\section{Hepatitis $\mathrm{C}$ virus}

At least 4.6 million persons are $\mathrm{HCV}$-antibody positive and approximately 3.5 million are currently infected with HCV. 
Most patients with acute HCV infections are largely asymptomatic and do not seek medical attention. ${ }^{41}$ The CDC estimates 3.3 cases of asymptomatic acute HCV for each newly diagnosed symptomatic acute HCV case. ${ }^{41}$ In the USA, the number of HCV-related deaths $(n=15106)$ exceeded the number of HIV/ AIDS-related deaths $(n=12734)$ for the first time in 2007 and has since continued to rise.

The most common modes of transmission of HCV occur through exposures to small quantities of blood via unsafe healthcare practices, injection practices, intravenous drug use, blood-tainted bodily fluids or objects, sexual transmission and transfusions. HCV can survive on environmental surfaces for roughly 16 hours. ${ }^{39}$ Failure to identify infected individuals is a major obstacle to appropriate care and successful control of HCV. Appropriately screening asymptomatic patients with identifiable risk factors for $\mathrm{HCV}$ is an important step towards improving the detection and treatment of affected individuals.

The theoretical risk of HCV transmission in sport has not been published. There are no documented reports of transmission of HCV through sports participation in isolated case reports. Confirmed cases of transmission of HCV between team mates sharing needles for performance-enhancing injections exist. ${ }^{15}$ HCV transmission has also been documented after bloody combat outside of the sanctioned combative sports setting. ${ }^{44}$

\section{BBPs in sport-related activity \\ Testing/Screening}

Mandatory screening for BBP is not medically justified as a condition for athletic participation or competition given the low risks of infection and transmission described above. ${ }^{1-9} 45$ These tests cannot be used effectively for prevention, the costs are excessive and there are additional logistical, legal and ethical considerations. $^{16}{ }^{45}$ Voluntary testing and screening may be recommended to all individuals, regardless of athletic participation, if one or more of the criteria which confer higher risk is $\mathrm{met}^{16}$ :

1. Multiple sexual partners.

2. Injections of drugs (including drugs of abuse and doping with ergogenic aids).

3. Sexual contact with at-risk individuals.

4. Sexually transmitted infections.

5. Blood transfusions before 1985 .

The CDC and United States Prevenative Services Task Force (USPSTF) both recommend HIV screening of at-risk adolescents and adults aged $15-65$ years. ${ }^{46} 47$ Evidence is insufficient at this time to recommend an optimum time interval between screenings. ${ }^{46} 47$ Both the CDC and USPSTF also recommend that persons at high risk for infection (eg, people with HIV, men who have sex with men, people who inject drugs, and endemic parts of the world) be screened for HBV and $\mathrm{HCV}^{48-50}$ Additionally, USPSTF recommends offering one-time screening for HCV to adults born between 1945 and $1965 .{ }^{51}$ However, the CDC recommends against testing asymptomatic individuals in the general population for $\mathrm{HBV}^{49}$ If testing is performed, then the ordering healthcare provider is responsible for ensuring that pretest and post-test counselling is available and testing is completed within the framework of state and federal law. ${ }^{45}$

Some specific sports' governing organisations require pre-participation screening for BBPs, including the International Federation of Associated Wrestling Styles, International Boxing Federation, International Amateur Boxing Association and various state boxing commissions. These groups have not published any evidence-based scientific rationale for their screening requirements. Athletes in these sports should have the ability to request testing if they participate in high-risk behaviours and may have an opportunity to opt out of sportrelated pre-participation BBP screening contingent on sportspecific regulations and rules. ${ }^{45}$

\section{Specific management and preventive measures for sports events and practices}

An understanding of the risk factors and development of precautionary procedures to reduce blood exposure is instrumental for decreasing the already small risk for transmission of BBPs in organised sports. ${ }^{52-54}$ Adherence to basic hygiene and standard precautions (formerly called universal precautions) is appropriate for all athletic settings. The following recommendations are intended to provide treatment guidelines for all providers delivering care in athletic settings:

1. Preparation: pre-event preparation includes proper care for pre-existing skin injuries or conditions that compromise the integrity of the protective skin barrier such as abrasions, existing or healing wounds, and dermatitis. These conditions may serve as a source of bleeding or as a point of entry for BBPs and should be covered until completely healed, with an occlusive dressing that will withstand the stress of competition to prevent transmission.

2. Supplies: supplies that reduce blood exposures and are compliant with standard precautions should be used for the care of all patients and be available to caregivers. These resources include latex or vinyl gloves, face/eye shields, soap/disinfectant, bleach (freshly prepared in a 1:10 dilution with tap water) or Environmental Protection Agency (EPA)-approved germicide, safer needles (eg, self-sheathing needles, blunted suture needles, needleless connectors and infusion sets), bandages or dressings, designated receptacles for soiled equipment or uniforms (with separate leak-proof bags or receptacles appropriately marked for uniforms and equipment contaminated with blood) and a punctureresistant sharps disposal container. ${ }^{55-61}$ It is recommended that participants in sporting events use squeeze-type water containers to avoid direct contact with the mouth as they drink as there is a potential risk of transmission through bleeding around the mouth. ${ }^{6263}$

3. Early recognition: during the sporting event, prompt recognition and appropriate response of active bleeding is the responsibility of officials, athletes and medical personnel. Participants with bleeding should be removed from the event as soon as practical. Bleeding must be controlled, and exposed mucus membranes should be flushed with water and wounds cleansed with soap and water. Antiseptic products are not recommended as they do not reduce the risk of BBP transmission and damage or compromise normal tissue repair. ${ }^{15286465}$ The wound must be covered with an occlusive dressing that can withstand the stress of the activity. Once bleeding is controlled and the wounds are properly covered, the player may return safely to competition. Any participant with exposed blood or blood-containing body fluids present should change that uniform and/or cover and control an area of active bleeding before returning to competition.

4. Reporting: participants should be educated that it is their obligation to report all wounds and injuries in a timely manner, including those recognised before the sporting activity, 
and wear sport-specific appropriate protective equipment at all times (ie, mouth guards).

5. Precautions: standard precautions must be followed for the care of all patients with the practice of hand hygiene before and after every patient contact. ${ }^{66-68}$ Appropriate gloves are required for all interactions when direct contact with blood, body fluids and other fluids containing blood can be anticipated. Gloves must be changed after treating each individual participant and hands should be washed with soap and water or antiseptic following glove removal.

6. Access to protective equipment: personal protective equipment (PPE): gloves, goggles, mask and fluid-resistant gown, as well as airway devices should be readily accessible. The lack of protective equipment should not delay emergency care for life-threatening injuries.

7. Decontamination: any equipment or playing surfaces (eg, wrestling mat) contaminated with blood or potentially infectious body fluids should be wiped immediately with paper towels or disposable cloths, and disinfected with a daily-prepared 1:10 ratio of bleach to water solution or EPA-approved germicide. ${ }^{61}$ The cleaned area should be dry before reuse and individuals cleaning the equipment or collecting soiled linen should wear appropriate PPE.

8. Postevent follow-up: postevent management may include re-evaluation and management of any wounds sustained during the sporting event, including but not limited to covering wounds, cuts and abrasions, debriding dirty wounds and suturing clean wounds. Participants should be provided with appropriate follow-up with medical personnel for proper medical evaluation, postexposure counselling and prophylaxis, as indicated. Blood-soiled uniforms and towels should be collected using standard precautions and laundered according to the appropriate protocol: in hot water at a temperature of at least $71^{\circ} \mathrm{C}\left(160^{\circ} \mathrm{F}\right)$ for 25 min cycles. ${ }^{61}$

9. Procedures: procedures performed in the training room and during practices must be governed by adherence to standard infectious precautions. Medical providers should be equipped with appropriate PPE when coming into contact with potential BBP. Blood, potential infectious body fluids or other fluids containing blood should be cleaned as previously described. Equipment handlers, laundry personnel and janitorial staff should adhere to standard precautions and be advised to wear gloves whenever contact with bloody equipment, clothing or other items may occur. Appropriate containers for the disposal of needles, syringes or scalpels should be available.

10. Universal precautions: adherence to blood exposure plans should be consistent. Complacency concerning adherence to standard (universal) precautions has been documented in a major sporting competition. ${ }^{69}$ Given anecdotal reports of transmission of HIV and HCV in bloody street fights, sports with rules against fighting (ie, all sports except North American professional hockey) should be emphasised and enforced.

11. Prophylaxis: pre-exposure and post-exposure prophylaxis for HIV, HBV and HCV should be based on the risk of exposure, except the hepatitis B vaccine. The strategy of vaccinating individual groups considered to be at high risk for contracting hepatitis $\mathrm{B}$ has not been successful in reducing the incidence of new infections, and universal vaccination of all individuals is recommended for prevention by the WHO, CDC, AAP, NFL and FIMS. ${ }^{70-75}$

12. Training: all personnel involved with sports should be trained in basic first aid and infection control, including the preventative measures outlined here.

\section{The effects of exercise on athletes living with BBPs and general principles of management}

Since the 1995 AMSSM and AOSSM statement, advances in the development of combination ART(cART) for HIV have transformed the infection from a fatal and progressive disease into a complex but manageable infection for those diagnosed who receive timely evidence-based care. Effective therapy results in a near-normal life span. ${ }^{76} \mathrm{HCV}$ had only been clinically recognised for 6 years in 1995, and available therapy was ineffective and had significant side effects. Today HCV-infected patients can benefit from the development of a growing number of direct-acting antiviral agents (DAA), which are well tolerated and curative in nearly all patients with treatment durations of $\leq 12$ weeks. ${ }^{77}$ HBV continues to decrease in prevalence secondary to global immunisation programmes and there are now six approved antiviral agents to manage the infection for those who have active disease. $^{78}$

\section{Effect of exercise on those infected with BBPs}

Exercise has been found to be beneficial to the health and wellbeing of individuals infected with HIV, HCV or HBV. Compared with controls, patients with chronic hepatitis have decreased strength, exercise time to exhaustion and performance, and increased liver enzyme elevation during endurance exercise bouts. $^{79-83}$ When these patients engaged in a regular structured exercise programme, they experienced improved aerobic capacity, insulin sensitivity, body mass index, quality of life, and pain and depression scores. ${ }^{8485}$

Moderate aerobic exercise increases CD4 levels in asymptomatic HIV-positive patients. Individuals with advanced stages of HIV infection may experience increased CD4 counts and CD4:CD8 ratio in response to aerobic exercise. ${ }^{86}$ However, intense exercise may impair the ability of HIV-positive patients to mobilise neutrophils and natural killer cells. ${ }^{8687}$ For patients on cART, moderate aerobic exercise decreases lipolysis and fatty acid oxidation, improves insulin sensitivity, decreases central adiposity, decreases anxiety and tension, and improves quality of life. ${ }^{88-91}$

Numerous systematic reviews have concluded that 20 min of aerobic exercise performed three times per week for as little as 5 weeks can improve the efficiency of oxygen consumption, body composition, insulin sensitivity, depression and other psychological symptoms. Participation in longer duration programmes inhibits neurocognitive decline, improves body composition, improves both lipid profiles and glucose levels, and increases $\mathrm{VO}_{2}$ max. ${ }^{92-96}$ Resistance exercise training increases muscle mass, strength, function and insulin sensitivity; decreases body fat; and improves lipid profiles in HIV-positive individuals. ${ }^{97-102}$

Recent systematic reviews have concluded that combining aerobic exercise with progressive resistance exercise in HIVinfected individuals improves cognition, insulin sensitivity, lean mass, upper and lower extremity strength, endurance, exercise time to exhaustion, $\mathrm{VO}_{2} \max$ and quality of life and depression scores. It also decreases resting heart rate. ${ }^{101-103}$ It does appear that combined programmes are safe for HIV-positive patients of either gender at nearly any age and result in significant overall improvement in health. ${ }^{103} 104$ 


\section{Exercise recommendations}

Exercise appears to improve overall general health and well-being with low risk of adverse effects for those individuals infected with HBV/HDV and HCV; thus, it is recommended that those with chronic hepatitis should exercise as tolerated. ${ }^{84}$ Those with acute hepatitis infection will need to limit the exercise intensity based on their general health status. Further research is needed to define specific exercise recommendations in those with acute or chronic HBV/HDV or HCV infections.

Moderate exercise is beneficial to the physical and psychological well-being of the HIV-positive patient, but strenuous exercise may be detrimental. ${ }^{86} 92$ HIV-infected individuals should begin exercising while healthy and maintain their exercise programme to help manage their illness and improve their quality of life. For healthy, asymptomatic HIV-positive individuals, unrestricted exercise is acceptable. For HIV-positive athletes with mild to moderate symptoms (eg, fatigue, menstrual changes, swollen lymph nodes, mild rashes, night sweats and so on) or low CD4 counts $(<200)$, strenuous, exhaustive exercise should be avoided. Athletes with AIDS may remain active as directed by symptomatology but should avoid strenuous exercise and reduce or stop training during acute, opportunistic illness.

\section{Treatment}

Appropriate care of BBP considers two goals: suppression and cure. Suppression of the infection to clinically undetectable levels is now achievable. For HIV-infected individuals, complete viral suppression is achievable in the vast majority of cases. In addition, viral suppression decreases transmission risk by both sexual and non-sexual routes. ${ }^{32} 105$ The second goal, specifically for HCV-infected patients, is to cure the infection with one of the many approved combination antiviral regimens. ${ }^{77}$ Following virological cure and in the absence of advanced liver damage, return to health is now achievable for the majority of treatmentcompliant patients. For HBV-infected patients, chronic and possibly lifelong viral suppression is possible, though the cure is currently not achievable in the majority. ${ }^{106}$ In summary, full viral suppression is a powerful means to reduce transmission for all BBPs.

\section{Education}

Healthcare providers should play a vital role in the education of patients, including athletes, regarding BBP. ${ }^{107}$ Athletes must be educated about the risks of blood-borne disease transmission via unsafe sexual practices and needle sharing. ${ }^{107} 108$ The consistent use of condoms with water-based lubricants is recommended as a means of reducing spread. The WHO strongly advises against the use of spermicides containing nonoxynol-9 stating that it does not protect against HIV infection and is less effective in preventing pregnancy than other methods. ${ }^{109}$ Furthermore, spermicides containing nonoxynol-9 may increase the risk of HIV infection in women using these products frequently. ${ }^{109}$ Besides sexual practices, sharing contaminated needles for any purpose, including tattoo applications, can increase the transmission risk of BBPs. ${ }^{110}$ Additionally, athletes should be educated to avoid sharing personal items, such as razors, toothbrushes and nail clippers, that carry BBP contamination risks. ${ }^{107}$ During sportrelated travel to certain parts of the world, players should be made aware of potential exposure to populations with higher prevalence of BBPs and higher risk medical scenarios including unscreened blood transfusion and injections with contaminated needles.
Athletes must be educated that the risk of transmission of BBPs during athletic competition is highly unlikely, both to provide comfort and dispel misconceptions regarding risks and routes of transmission. ${ }^{111}$ Practical hygienic measures (eg, prompt application of first aid to bleeding injuries) should be emphasised, and athletes must understand that it is in their best interest to provide timely reports regarding significant injuries to appropriate personnel.

The athletic setting affords unique opportunities for educational initiatives aimed at reducing fear and misconceptions concerning BBP transmission among individuals. Sports can be a vehicle for information sharing and may be used alongside other strategies to raise awareness of the HIV epidemic and to facilitate prevention. ${ }^{112}$ The convening power of sport can be effectively used to tackle stigma and discrimination as well as influence the most vulnerable populations with messages about HIV/AIDS prevention. The United Nations (UN) has highlighted sport as an effective platform to increase HIV/AIDS knowledge and awareness. ${ }^{113}$ For example, the first HIV/AIDS advertisement to air during Super Bowl Sunday was part of the KNOW HIV/AIDS global media campaign launched by Viacom and the Henry J. Kaiser Family Foundation in $2004 .^{114}$ This form of mass media was proven effective in reaching a national audience and drawing attention to the global HIV/AIDS pandemic. ${ }^{113}$ Such examples demonstrate how sports can empower a community with facts, skills and means for protection to halt the spread of an epidemic. ${ }^{113}$ Programmes should also recognise the ability of athletes to serve as positive role models and educators, capable of connecting with at-risk groups in a manner not accessible to members of the medical community. ${ }^{113} 115$

\section{SUMMARY}

The spread of BBPs has been proposed as a potential concern in athletic participation, yet the confirmed transmission of BBPs during sport is exceedingly rare. There are no well-documented reports of HIV, HCV or HDV transmission during sport. There is also no evidence for universal testing for BBPs as a specific requirement for participation in sports. Competitive athletes and non-athletes should follow appropriate general public health agency recommendations for screening for BBPs, considering their individual risk factors and exposures. Although the risk of transmission for any BBP in the athletic setting is minute, common sense dictates that standard precautions be followed by anyone providing care to athletes. Exercise and athletic participation are compatible with a healthy lifestyle for everyone, including those persons living with BBPs. Those with acute symptomatic BBP infection should limit exercise intensity based on their current health status. Exercise and training do not appear to be harmful to the health of asymptomatic athletes infected with BBP pathogens; therefore, moderate levels of exercise should be encouraged for those with BBP. Education is the key tool for preventing BBP transmission. Future research considerations may include evaluation of the prevalence of $\mathrm{BBP}$ infections in competitive athletes, the effects of long-term, intense training on infected athletes, and the effects of BBP treatment therapies on performance.

\footnotetext{
Author affiliations

${ }^{1}$ Departments of Family and Community Medicine, University of New Mexico Health Sciences Center, Albuquerque, New Mexico, USA

${ }^{2}$ Sports Medicine Division, Department of Orthopedics and Rehabilitation, University

of New Mexico Health Sciences Center, Albuquerque, New Mexico, USA

${ }^{3}$ University of California, Berkeley, California, USA

${ }^{4}$ USF Health Morsani College of Medicine, Tampa, Florida, USA

${ }^{5}$ TMI Sports Medicine \& Orthopedic Surgery, Frisco, Texas, USA
} 
${ }^{6}$ Cleveland Clinic, Cleveland, USA

Department of Orthopedic Surgery, Howard Hughes Medical Institute, University of Texas, Southwestern Medical Center at Dallas, Dallas, Texas, USA

${ }^{8}$ Department of Family and Community Medicine, University of Arizona, Tucson, Arizona, USA

${ }^{9}$ University of Colorado, Denver, USA

${ }^{10}$ Department of Family Medicine, University of Washington, Seattle, Washington, USA

${ }^{11}$ Department of Family Medicine, Oregon Health and Science University, Portland, Oregon, USA

Contributors All authors of this submitted manuscript have made substantial contributions to the conception or design of the work, or the acquisition, analysis or interpretation of data. They have all been involved in drafting the work or revising it critically for important intellectual content. They have all given final approval of the version published. They all in agreement to be accountable for all aspects of the work in ensuring that questions related to the accuracy or integrity of any part of the work are appropriately investigated and resolved.

Funding The authors have not declared a specific grant for this research from any funding agency in the public, commercial or not-for-profit sectors.

Competing interests None declared.

Provenance and peer review Not commissioned; internally peer reviewed.

\section{ORCID iDs}

Christopher McGrew http://orcid.org/0000-0001-7886-6697

Rathna Nuti http://orcid.org/0000-0003-2004-9795

\section{REFERENCES}

1 Human Immunodeficiency Virus (HIV) and Other Blood-Borne Pathogens in Sports. Am J Sports Med 1995:23:510-4.

2 Blood-borne pathogens guidelines for athletic trainers. J Athl Train 1995;30:203-4.

3 Centers for Disease Control and Prevention. HIVIAIDS National prevention information network HIVIAIDS and Sports (website). 1996 www.ed.state.nh.us/ HealthHIVAIDS/HIVPolicy (Accessed 1 Jun 2017).

4 International Federation of Sports Medicine. AIDS and Sports: FIMS Position Statement. 1997 http://www.fims.org/files/6314/2056/2140/PS2-AIDS-and-Sports. pdf (Accessed 21 Dec 2017).

5 Sports Medicine Australia. Infectious Diseases with particular reference to HIV (AIDS) and Viral Hepatitis (B, C, etc.). 1997 http://www.volleyballaustralia.org.au/page/ policies http://www.volleyballaustralia.org.au/_literature_152765/Sports_Medicine_ Australia_Infectious_Diseases_Information (Accessed 21 Dec 2017)

6 Committee on Sports Medicine and Fitness. Human immunodeficiency virus and other blood-borne viral pathogens in the athletic setting. Pediatrics 1999:104:1400-3.

7 Jeffery MR. Canadian academy of sport and exercise medicine. Position statement: HIV as it relates to sport. 2007. https://casem-acmse.org/wp-content/uploads/2013/ 07/HIV-as-it-relates-to-Sport-2007.pdf (Accessed 1 Jun 2017).

8 The National Collegiate Athletic Association. 2014-2015 NCAA Sports Medicine Handbook. 25th ed. Indianapolis: National Collegiate Athletic Association, 2014. http://www.ncaapublications.com/productdownloads/MD15.pdf. (Accessed 1 Jun 2017).

9 National Federation of State High School Associations. NFHS website. https:// www.nfhs.org/sports-resource-content/general-guidelines-for-sports-hygiene-skin infections-and-communicable-diseases/ (Accessed 1 Jun 2017).

10 Siebert DJ, Lindschau PB, Burrell CJ. Lack of evidence for significant hepatitis B transmission in Australian Rules footballers. Med J Aust 1995;162:312-3.

11 Passos ADC, Figueiredo JFdeC, Martinelli AdeLC, et al. Hepatitis C among former athletes: association with the use of injectable stimulants in the past. Mem Inst Oswaldo Cruz 2008;103:809-12.

12 Kordi R, Neal K, Pourfathollah AA, et al. Risk of hepatitis $b$ and $c$ infections in tehranian wrestlers. J Ath/ Train 2011;46:445-50.

13 Jaworski CA, Donohue B, Kluetz J. Infectious disease. Clin Sports Med 2011;30:575-90.

14 Dorman JM. Contagious diseases in competitive sport: what are the risks? J Am Coll Health 2000:49:105-9.

15 Kordi R, Wallace WA. Blood borne infections in sport: risks of transmission, methods of prevention, and recommendations for hepatitis B vaccination. Br J Sports Med 2004;38:678-84

16 Gutierrez RL, Decker CF. Blood-borne infections and the athlete. Dis Mon 2010;56:436-42

17 Hosoglu S, et al. Transmission of hepatitis $\mathrm{C}$ by blood splash into conjunctiva in a nurse. Am J Infect Control 2003;31:502-4.

18 Rosen HR. Acquisition of hepatitis C by a conjunctival splash. Am J Infect Control 1997;25:242-7.
19 Sartori M, La Terra G, Aglietta M, et al. Transmission of hepatitis C via blood splash into conjunctiva. Scand J Infect Dis 1993:25:270-1.

20 Mahboobi N, Porter SR, Karayiannis P, et al. Dental treatment as a risk factor for hepatitis B and C viral infection: a review of the recent literature. J Gastrointestin Liver Dis 2013;22:79-86

21 Hyder Q, Burhan-ul-Haq M, Rashid R, et al. Non-conventional transmission of hepatitis C: a true possibility ignored. J Pak Med Assoc 2009;59:430-3.

22 Rogers MF, White CR, Sanders $R$, et al. Lack of transmission of human immunodeficiency virus from infected children to their household contacts. Pediatrics 1990;85:210-4

23 Rivero A, Santos J, Márquez M, et al. Intrafamilial, non-sexual, transmission of the human immunodeficiency virus. Rev Clin Esp 1989;185:440-2.

24 Lock G, Dirscherl M, Obermeier F, et al. Hepatitis C - contamination of toothbrushes: myth or reality?. J Viral Hepat 2006;13:571-3.

25 Global Statistics. https://www.hiv.gov/hiv-basics/overview/data-and-trends/globalstatistics.

26 Hall HI, Song R, Tang T, et al. HIV Trends in the united states: Diagnoses and estimated incidence. JMIR Public Health Surveill 2017;3:e8.

27 Cohen MS. HIV infection: risk factors and prevention strategies. UpToDate. https:// www.uptodate.com/contents/hiv-infection-risk-factors-and-prevention-strategies (Accessed 15 Jun 2017).

28 Torre D, Sampietro C, Ferraro G, et al. Transmission of HIV-1 infection via sports injury. The Lancet 1990;335:1105.

29 Goodman RA, Thacker SB, Solomon SL, et al. Infectious diseases in competitive sports. JAMA 1994;271:862-7

30 Brown LS, Drotman DP, Chu A, et al. Bleeding injuries in professional football: estimating the risk for HIV transmission. Ann Intern Med 1995;122:271-4.

31 O'Farrell N, Tovey SJ, Morgan-Gapnei P. Transmission of HIV-1 infection after a fight. The Lancet 1992;339:246.

32 Cohen MS, Chen YQ, McCauley M, et al. Prevention of HIV-1 Infection with Early Antiretroviral Therapy. N Engl J Med Overseas Ed 2011;365:493-505.

33 Schweitzer A, Horn J, Mikolajczyk RT, et al. Estimations of worldwide prevalence of chronic hepatitis B virus infection: a systematic review of data published between 1965 and 2013. Lancet 2015;386:1546-55.

34 . https://www.cdc.gov/hepatitis/statistics/index.htm and https://www.hhs.gov/ hepatitis/learn-about-viral-hepatitis/hepatitis-b-basics/index.html

35 Bond WW, Favero MS, Petersen NJ, et al. Survival of hepatitis B virus after drying and storage for one week. Lancet 1981;1:550-1.

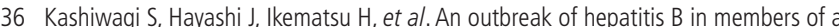
high school sumo wrestling club. JAMA 1982;248:213-4.

37 Tobe K, Matsuura K, Ogura T, et al. Horizontal transmission of hepatitis B virus among players of an American football team. Arch Intern Med 2000;160:2541-5.

38 Ringertz 0, Zetterberg B. Serum hepatitis among Swedish track finders. An epidemiologic study. N Engl J Med 1967;276:540-6.

39 Kamili S, Krawczynski K, McCaustland K, et al. Infectivity of hepatitis C virus in plasma after drying and storing at room temperature. Infect Control Hosp Epidemiol 2007;28:862-7

40 Hsieh TH, Liu CJ, Chen DS, et al. Natural course and treatment of hepatitis D virus infection. J Formos Med Assoc 2006;105:869-81.

41 Lempp FA, Ni Y, Urban S. Hepatitis delta virus: insights into a peculiar pathogen and novel treatment options. Nat Rev Gastroenterol Hepatol 2016;13:580-9.

42 Noureddin M, Gish R. Hepatitis delta: epidemiology, diagnosis and management 36 years after discovery. Curr Gastroenterol Rep 2014;16:365

43 Farci P. Delta hepatitis: an update. J Hepatol 2003:39:212-9.

44 Abel S, Césaire R, Cales-Quist D, et al. Occupational transmission of human immunodeficiency virus and hepatitis $C$ virus after a punch. Clin Infect Dis 2000:31:1494-5.

45 Whitehill WR, Wright KE. Delphi Study: HIVIAIDS and the athletic population. J Ath/ Train 1994:29:114-9.

46 Branson BM, Handsfield HH, Lampe MA, et al. Revised recommendations for HIV testing of adults, adolescents, and pregnant women in health-care settings. Center for disease control and prevention website. 2006. https://www.cdc.gov/mmwr/ preview/mmwrhtml/rr5514a1.htm (Accessed August 16, 2017.).

47 Final Recommendation Statement: Human Immunodeficiency Virus (HIV) Infection: Screening. US Preventive Task Force website. 2013. https://www. uspreventive servicestaskforce.org/Page/Document/RecommendationStatementFinal/humanimmunodeficiency-virus-hiv-infection-screening\#consider (Accessed 16 Aug 2017).

48 Hepatitis B Virus Infection: Screening, 2014. U.S. Preventive task force website. 2014. https://www.uspreventiveservicestaskforce.org/Page/Document/ UpdateSummaryFinal/hepatitis-b-virus-infection-screening-2014 (Accessed 21 Aug 2017).

49 New Guidelines for Hepatitis B Screening. HIV and Hepatitis website. 2014 http:// www.hivandhepatitis.com/hepatitis-b/hepatitis-b-topics/hbv-testing-diagnosis/4521 new-guidelines-for-hepatitis-b-screening (Accessed 21 Aug 2017).

50 . Hepatitis C: Screening. US Preventive Task Force website. https://www. uspreventive servicestaskforce.org/Page/Document/UpdateSummaryFinal/hepatitis-c-screening. 2013. Accessed August 21, 2017 
51 Getchell JP, Wroblewski KE, DeMaria A, et al. Center for Disease Control and Prevention website. 2013 https://www.cdc.gov/mmwr/pdf/wk/mm62e0507a2.pdf (Accessed 21 Aug 2017).

52 Mitchell H, Hughes G. Recent epidemiology of sexually transmissible enteric infections in men who have sex with men. Curr Opin Infect Dis 2018;31:50-56.

53 Haire B, Whitford K, Kaldor JM. Blood donor deferral for men who have sex with men: still room to move. Transfusion 2017.

54 Mast EE, Goodman RA, Bond WW, et al. Transmission of blood-borne pathogens during sports: risk and prevention. Ann Intern Med 1995;122:283-5.

55 Kuhar DT, Henderson DK, Struble KA, et al. Updated US Public Health Service guidelines for the management of occupational exposures to human immunodeficiency virus and recommendations for postexposure prophylaxis. Infect Control Hosp Epidemiol 2013;34:875-92.

56 Allen JI, Kaushal N. New Models of Gastroenterology Practice. Clin Gastroenterol Hepatol 2018;16:3-6.

57 Ford N, Mayer KH. World health organization guidelines on postexposure prophylaxis for hiv: Recommendations for a public health approach. Clin Infect Dis 2015;60 Suppl 3:S161-S164.

58 Bloodborne Pathogens and Needlestick Prevention. Occupational safety and health administration website. https://www.osha.gov/SLTC/bloodbornepathogens/ recognition.html (Accessed 25 Mar 2014).

59 Henderson DK. Management of needlestick injuries: a house officer who has a needlestick. JAMA 2012;307:75-84.

60 Askarian M, Yadollahi M, Kuochak F, et al. Precautions for health care workers to avoid hepatitis B and C virus infection. Int J Occup Environ Med 2011;2:191-8.

61 CDC: Guidelines for Environmental Infection Control in Health-Care Facilities. 2003 (Accessed 13 Jul 2018). https://www.cdc.gov/mmwr/preview/mmwrhtml/rr5210a1. html

62 Stop Sticks Campaign User's Guide and Resources. Center for Disease Control and Prevention website. 2011. https://www.cdc.gov/niosh/stopsticks/ (Accessed 25 Mar 2014).

63 About the Workbook for Designing, Implementing \& Evaluating a Sharps Injury Prevention Program. Center for Disease Control and Prevention website. 2015 https://www.cdc.gov/sharpssafety/resources.html (Accessed 25 Mar 2014)

64 Berahou H, Serhier Z, Housbane S, et al. Occupational exposure to blood among medical students in Casablanca (Morocco): Analysis of knowledge and practices Sante Publique 2017:29:579-84.

65 Schillie S, Murphy TV, Sawyer M, et al. CDC guidance for evaluating health-care personnel for hepatitis $B$ virus protection and for administering postexposure management. MMWR Recomm Rep 2013;62:1.

66 Atiyeh BS, Dibo SA, Hayek SN. Wound cleansing, topical antiseptics and wound healing. Int Wound J 2009;6:420-30.

67 Moscati RM, Reardon RF, Lerner EB, et al. Wound irrigation with tap water. Acad Emerg Med 1998;5:1076-80.

68 Loeb T, Loubert G, Templier F, et al. [latrogenic gas embolism following surgical lavage of a wound with hydrogen peroxide]. Ann Fr Anesth Reanim 2000;19:108-10.

69 Furin JJ. Blood exposure at the 2010 International Federation of Football Association World Cup: time for universal adaptation of universal precautions. Clin I Sport Med 2011:21:264-5.

70 Siegel JD, Rhinehart E, Jackson M, et al. 2007 Guideline for isolation precautions: Preventing transmission of infectious agents in health care settings. Am J Infect Control 2007;35:S65-S164.

71 Garner JS. Hospital Infection Control Practices Advisory Committee. Guideline for Isolation Precautions in Hospitals. Infect Control Hosp Epidemiol 1996:17:53-80.

72 Whitehouse JD, Sexton DJ, Kirkland KB. Infection control: past, present, and future issues. Compr Ther 1998:24:71-7.

73 World Health Organization (2002). Hepatitis B. www.who.int/emc documents/ hepatitis/docs/whocdscsrlyo20022/index.html.

74 Centers for Disease Control and Prevention, National prevention information network. HIV/AIDS and Sports. 1996 Wwwed.state.nh.us/HealthHIVAIDS/HIVPolic yTrainingResourcespdf.

75 International Federation of Sports Medicine. AIDS and sports, FIMS Position Statement. 1997 www.fims.org/fims/frames.asp.

76 Trickey A, May MT, Vehreschild J-J, et al. Survival of HIV-positive patients starting antiretroviral therapy between 1996 and 2013: a collaborative analysis of cohort studies. Lancet HIV 2017:4:e349-e356.

77 Falade-Nwulia O, Suarez-Cuervo C, Nelson DR, et al. Oral Direct-Acting Agent Therapy for Hepatitis C Virus Infection: A Systematic Review. Ann Intern Med 2017:166:637-48.

78 Shiffman ML. Universal screening for chronic hepatitis C virus. Liver Int 2016;36 Suppl 1:62-6.

79 Chen YJ, Chen KW, Shih YL, et al. Chronic hepatitis B, nonalcoholic steatohepatitis and physical fitness of military males: CHIEF study. World J Gastroenterol 2017:23:4587-94.

80 Chou SL, Chou MY, Wang YH, et al. The impact of chronic carrier of hepatitis $B$ virus on liver function in a 7-day ultramarathon race. J Chin Med Assoc 2016;79:179-84
81 Abd El-Kader SM, Al-Jiffri OH, Al-Shreef FM. Liver enzymes and psychological wellbeing response to aerobic exercise training in patients with chronic hepatitis C. Afr Health Sci 2014;14:414-9.

82 Loria A, Doyle K, Weinstein AA, et al. Multiple factors predict physical performance in people with chronic liver disease. Am J Phys Med Rehabil 2014;93:470-6.

83 Chiu YH, Hou SK, How CK, et al. Influence of a 100-km ultra-marathon on hepatitis B carrier runners. Int J Sports Med 2013;34:841-5.

84 McKenna O, Cunningham C, Gissane C, et al. Management of the extrahepatic symptoms of chronic hepatitis $C$ : feasibility of a randomized controlled trial of exercise. Am J Phys Med Rehabil 2013;92:504-12.

85 Pattullo V, Duarte-Rojo A, Soliman W, et al. A 24-week dietary and physical activity lifestyle intervention reduces hepatic insulin resistance in the obese with chronic hepatitis C. Liver Int 2013;33:410-9.

86 Eichner ER, Calabrese LH. Immunology and exercise. Physiology, pathophysiology, and implications for HIV infection. Med Clin North Am 1994;78:377-88.

87 Deresz LF, Sprinz E, Kramer AS, et al. Regulation of oxidative stress in response to acute aerobic and resistance exercise in HIV-infected subjects: a case-control study. AIDS Care 2010;22:1410-7.

88 Cade WT, Reeds DN, Mittendorfer B, et al. Blunted lipolysis and fatty acid oxidation during moderate exercise in HIV-infected subjects taking HAART. Am J Physiol Endocrinol Metab 2007:292:E812-E819.

89 LaPerriere A, Fletcher M, Antoni M, et al. Aerobic Exercise Training in an AIDS Risk Group*. Int J Sports Med 1991:12:S53-S57.

90 Mutimura E, Stewart A, Crowther NJ, et al. The effects of exercise training on quality of life in HAART-treated HIV-positive Rwandan subjects with body fat redistribution. Qual Life Res 2008;17:377-85.

91 Yarasheski KE, Cade WT, Overton ET, et al. Exercise training augments the periphera insulin-sensitizing effects of pioglitazone in HIV-infected adults with insulin resistance and central adiposity. Am J Physiol Endocrinol Metab 2011:300:E24 3-E251.

92 Vancampfort D, Mugisha J, Richards J, et al. Physical activity correlates in people living with HIVIAIDS: a systematic review of 45 studies. Disabil Rehabil 2018:40:1-12.

93 Pedro RE, Guariglia DA, Peres SB, et al. Effects of physical training for people with HIV-associated lipodystrophy syndrome: a systematic review. J Sports Med Phys Fitness 2017:57:685-94.

94 O'Brien KK, Tynan AM, Nixon SA, et al. Effectiveness of Progressive Resistive Exercise (PRE) in the context of HIV: systematic review and meta-analysis using the cochrane collaboration protocol. BMC Infect Dis 2017; 17:268.

95 O'Brien KK, Tynan AM, Nixon SA, et al. Effectiveness of aerobic exercise for adults living with HIV: systematic review and meta-analysis using the Cochrane Collaboration protocol. BMC Infect Dis 2016:16:182

96 Gomes Neto M, Conceição CS, Oliveira Carvalho V, et al. Effects of combined aerobic and resistance exercise on exercise capacity, muscle strength and quality of life in hiv-infected patients: A systematic review and meta-analysis. PLoS One 2015:10:e0138066

97 Hand GA, Lyerly GW, Jaggers JR, et al. Impact of aerobic and resistance exercise on the health of HIV-infected persons. Am J Lifestyle Med 2009:3:489-99.

98 Bessa A, Lopez JC, DI Masi F, et al. Lymphocyte CD4+ cell count, strength improvements, heart rate and body composition of HIV-positive patients during a 3-month strength training program. J Sports Med Phys Fitness 2017;57:1051-6.

99 Zanetti HR, Cruz LG, Lourenço CL, et al. Non-linear resistance training reduces inflammatory biomarkers in persons living with HIV: A randomized controlled trial. Eur J Sport Sci 2016;16:1232-9.

100 Mkandla K, Myezwa H, Musenge E. The effects of progressive-resisted exercises on muscle strength and health-related quality of life in persons with HIV-related polyneuropathy in Zimbabwe. AIDS Care 2016:28:639-43.

101 Santos WR, Santos WR, Paes PP, et al. Impact of strength training on bone mineral density in patients infected with hiv exhibiting lipodystrophy. J Strength Cond Res 2015:29:3466-71.

102 Dudgeon WD, Jaggers JR, Phillips KD, et al. Moderate-intensity exercise improves body composition and improves physiological markers of stress in hiv-infected men. Isrn Aids 2012:2012:1-14.

103 Zanetti HR, da Cruz LG, Lourenço CL, et al. Does nonlinear resistance training reduce metabolic syndrome in people living with HIV? A randomized clinical trial. J Sports Med Phys Fitness 2017;57:678-84.

104 Hand GA, Phillips KD, Dudgeon WD, et al. Moderate intensity exercise training reverses functional aerobic impairment in HIV-infected individuals. AIDS Care 2008;20:1066-74

105 Cohen MS, Chen YQ, McCauley M, et al. Antiretroviral therapy for the prevention of HIV-1 transmission. N Eng/ J Med Overseas Ed 2016;375:830-9.

106 Centers for Disease Control and Prevention. Hepatitis B information for health professionals: hepatitis B FAQs for health professionals. 2015 http://www.cdc.gov/ hepatitis/HBV/index.htm.

107 Clem KL, Borchers JR. HIV and the athlete. Clin Sports Med 2007;26:413-24.

108 Minooee A, Wang J, Gupta GK. Sports: The infectious hazards. Microbio/ Spectr $2015 ; 3$. 
109 Powell C, Farley F. Nonoxynol-9 ineffective in preventing HIV infection. World Health Organization website. http://www.who.int/mediacentre/news/notes/release55/en/ (Accessed 10 Aug 2017)

110 Antinori A, Arendt G, Becker JT, et al. Updated research nosology for HIV-associated neurocognitive disorders. Neurology 2007;69:1789-99.

111 Feller A, Flanigan TP. HIV-infected competitive athletes. What are the risks? What precautions should be taken? J Gen Intern Med 1997;12:243-6.

112 Koss JO, Alexandrova A. Essay: HIVIAIDS prevention and peace through sport. Lancet 2005;366 Suppl 1:S3-S4.

113 Maro CN, Roberts GC, Sørensen M. Using sport to promote HIV/AIDS education for at-risk youths: an intervention using peer coaches in football. Scand J Med Sci Sports 2009; 19:129-41.
114 Super Bowl ad part of HIV/AIDS campaignSuper Bowl ad part of HIVI AIDS campaign. Viacom and Henry J 2004. Kaiser Family Foundation: Seattle,Washington.

115 Beres LK. Missed opportunities: HIV and the 2010 FIFA World Cup. Public Health 2011;125:725-6.

116 McGrew CA. Blood-borne pathogens in sports. In: Garrett WE, Kirkendall DT, Squire DL, eds. Practices of Primary Care Sports Medicine. Philadelphia: Lippincott Williams \& Wilkins, 2001:p247.

117 Ullum H, Palmø J, Halkjaer-Kristensen J, et al. The effect of acute exercise on lymphocyte subsets, natural killer cells, proliferative responses, and cytokines in HIVseropositive persons. J Acquir Immune Defic Syndr 1994;7:1122-33. 